\title{
Corrigendum: Autonomic Nervous System Correlates of Speech Categorization Revealed Through Pupillometry
}

\author{
Gwyneth A. Lewis ${ }^{1,2}$ and Gavin M. Bidelman ${ }^{1,2,3 *}$ \\ ${ }^{1}$ Institute for Intelligent Systems, The University of Memphis, Memphis, TN, United States, ${ }^{2}$ School of Communication \\ Sciences and Disorders, The University of Memphis, Memphis, TN, United States, ${ }^{3}$ Department of Anatomy and \\ Neurobiology, University of Tennessee Health Sciences Center, Memphis, TN, United States
}

Keywords: pupillometry, categorical perception, speech-in-noise (SIN) perception, listening effort, eye behavior

\section{A Corrigendum on}

Autonomic Nervous System Correlates of Speech Categorization Revealed Through Pupillometry

by Lewis, G. A., and Bidelman, G. M. (2020). Front. Neurosci. 13:1418. doi: 10.3389/fnins.2019.01418

In the original article, there was an error in the text. The methods described the noise masker as a four-talker babble (three women and one man) extracted from the clinical QuickSIN test (e.g., Killion et al., 2004), which was incorrect. The masker was actually a speech-shaped noise based on the long-term power spectrum.

A correction has been made to the METHODS section, subsection Speech Stimuli and Behavioral Task paragraph 2:

Tokens were $100 \mathrm{~ms}$, including $10 \mathrm{~ms}$ of rise/fall time to reduce spectral splatter in the stimuli.

OPEN ACCESS

Edited and reviewed by:

Yi Du,

Institute of Psychology (CAS), China

*Correspondence:

Gavin M. Bidelman

gmbdlman@memphis.edu

Specialty section:

This article was submitted to Auditory Cognitive Neuroscience,

a section of the journal

Frontiers in Neuroscience

Received: 23 January 2020

Accepted: 03 February 2020

Published: 19 February 2020

Citation:

Lewis GA and Bidelman GM (2020)

Corrigendum: Autonomic Nervous

System Correlates of Speech

Categorization Revealed Through

Pupillometry. Front. Neurosci. 14:132.

doi: 10.3389/fnins.2020.00132
Each contained identical voice fundamental (F0), second (F2), and third formant (F3) frequencies (F0: 150, F2: 1090, and F3: $2350 \mathrm{~Hz}$ ). The F1 was parameterized over five equal steps between 430 and $730 \mathrm{~Hz}$ such that the resultant stimulus set spanned a perceptual phonetic continuum from /u/ to /a/ (Bidelman et al., 2013). Speech stimuli were delivered binaurally at $75 \mathrm{~dB}$ SPL through shielded insert earphones (ER-2; Etymotic Research) coupled to a TDT RP2 processor (Tucker Davis Technologies). This same speech continuum was presented in one of three noise blocks to vary SNR: unmasked, $0 \mathrm{~dB}$ SNR, $-5 \mathrm{~dB}$ SNR. The masker was a speech-shaped noise based on the long-term power spectrum (LTPS) of the vowel set. While we typically use speech babble in our ERP studies, pilot testing showed this type of noise was too difficult for concurrent vowel identification, necessitating the use of simpler LTPS noise. The noise was presented continuously so that it was not time-locked to the stimulus presentation. Block order was randomized within and between participants.

The authors apologize for this error and state that this does not change the scientific conclusions of the article in any way. The original article has been updated.

\section{REFERENCES}

Bidelman, G. M., Moreno, S., and Alain, C. (2013). Tracing the emergence of categorical speech perception in the human auditory system. Neuroimage 79, 201-212. doi: 10.1016/j.neuroimage.2013.04.093

Copyright (c) 2020 Lewis and Bidelman. This is an open-access article distributed under the terms of the Creative Commons Attribution License (CC BY). The use, distribution or reproduction in other forums is permitted, provided the original author(s) and the copyright owner(s) are credited and that the original publication in this journal is cited, in accordance with accepted academic practice. No use, distribution or reproduction is permitted which does not comply with these terms. 